\title{
How well does the HadGEM2-ES coupled model represent the Southern Hemisphere storm tracks?
}

Article

Accepted Version

Dias da Silva, P. E., Hodges, K. I. and Coutinho, M. M. (2021) How well does the HadGEM2-ES coupled model represent the Southern Hemisphere storm tracks? Climate Dynamics, 56. pp. 1145-1162. ISSN 0930-7575 doi:

https://doi.org/10.1007/s00382-020-05523-9 Available at https://centaur.reading.ac.uk/95263/

It is advisable to refer to the publisher's version if you intend to cite from the work. See Guidance on citing.

To link to this article DOI: http://dx.doi.org/10.1007/s00382-020-05523-9

Publisher: Springer

All outputs in CentAUR are protected by Intellectual Property Rights law, including copyright law. Copyright and IPR is retained by the creators or other copyright holders. Terms and conditions for use of this material are defined in the End User Agreement.

www.reading.ac.uk/centaur 
Central Archive at the University of Reading

Reading's research outputs online 


\title{
How well does the HadGEM2-ES Coupled Model represent the Southern Hemisphere Storm Tracks?
}

\author{
Philipp Edson Dias da Silva*[1] - Kevin Ivan Hodges[2] • Mariane \\ Mendes Coutinho[1]
}

Received: date / Accepted: date

1 Abstract This study presents an assessment of the 26 ability of the Hadley Centre Global Environment Model 27 version 2 - Earth system configuration (HadGEM2-ES) ${ }_{28}$ - in simulating the mid-latitude storm tracks over the 29 Southern Hemisphere (SH). The storm tracks are pri- 30 marily assessed using cyclone tracking using data from ${ }_{31}$ a 4 member ensemble of 27-year simulations of HadGEMzES over the historical period, and the European Centre 33 for Medium-Range Weather Forecasts (ECMWF) In- 34 terim Reanalysis (ERA-Interim). Both winter and sum- 35 mer periods are considered and contrasted. Results show 36 that the storm track (ST) climatology of HadGEM2- 37 ES presents similar patterns to those of the reanalysis. 38 However, the model tends to represent the austral win- 39 ter ST position with an equatorward bias and a zonal 40 bias in the spiral towards the pole. The main differences 41 were found during the austral winter, with large track 42 density biases over the Indian Ocean indicating a poor representation of the ST in this specific region. This ${ }_{44}^{43}$ was found to be related to two factors. First, the large negative genesis biases over South America, Antarctic Peninsula and the Antarctic coast. Second, the model ${ }_{45}$ resolution and the representation of the Andes Mountains in South America. The link between STs and the 46 large-scale circulation is examined and shows at upper 47

[1]

Center of Earth System Science (CCST),

National Institute for Space Research (INPE),

So Jos dos Campos - SP, Brazil

* Corresponding author: Philipp Edson Dias da Silva

E-mail: philipp.edson@gmail.com

Orcid: 0000-0001-5341-3843

[2]

Department of Meteorology,

University of Reading,

Reading, United Kingdom levels an equatorward jet position bias of the subtropical jet and a negative bias in the eddy-driven, associated with a large cold bias over the extratropical and polar regions. The analysis of the large-scale circulation shows that the split jet during winter has problems in the model linked to these biases, including geopotential anomaly and sea surface temperature biases. Consequently, in general the track densities over the Southern oceans are underestimated in the austral winter. During summer, the results show the STs move poleward and there is a single eddy-driven jet, which is represented relatively well compared with the winter situation. These factors tend to reduce the differences seen in the cyclone track distribution biases. Although the model has biases in the ST behaviour in the $\mathrm{SH}$ it is still considered that these do not preclude this model being used for perturbation and future projection studies.

Keywords Cyclones · Storm Tracks · Climatology · HadGEM2-ES · ERA-Interim · Southern Hemisphere

\section{Introduction}

Extratropical cyclones play an important role in the transport of energy and moisture from low latitudes to polar regions. They are synoptic scale ${ }^{1}$ weather systems that tend to occur most frequently in confined regions known as the storm tracks. The aim of this study is to determine how well the Southern Hemisphere (SH) storm tracks are represented in the historical experiment of Hadley Centre Global Environment Model version 2 Earth System (HadGEM2-ES) (Jones et al 2011) when contrasted with the European Centre for Medium-Range Weather Forecasts (ECMWF)

1 From several hundred kilometres to several thousand kilometres. 
Interim Reanalysis (ERA-Interim). This will then pro- 54 vide confidence in using HadGEM2-ES to investigate ${ }_{55}$ the importance of the Amazon Forest to the SH storm 56 tracks under future climate scenarios of greenhouse gas ${ }_{57}$ emissions, to be reported in a second publication. $\quad{ }_{58}$

Cyclones that constitute the storm tracks can lead 59 to extreme weather in the middle latitudes, such as cold 60 air outbreaks (Sprenger et al 2013), extreme precipita- 61 tion (Silva Dias et al 2013) and intense winds (Parise 62 et al 2009). Furthermore, as discussed in IPCC (2013), 63 the intensity of extreme weather has increased in recent 64 years, emphasizing the importance of improving the un- 65 derstanding of storm tracks. In particular for the $\mathrm{SH}, 66$ several previous storm track (ST) studies such as Tal- 67 jaard (1972); Gan and Rao (1991); Jones and Simmonds 68 (1993); Berbery and Vera (1996); Sinclair (1997); Sim- 69 monds and Keay (2000); Hoskins and Hodges (2005); Hodges et al (2011) and others, using observational data and reanalyses, have found important patterns and links with the mean flow and large-scale circulation. From a climate model perspective, while much progress has been made in simulating the Northern Hemisphere (NH) ST features (e.g. Catto et al $(2010,2011)$; Zappa $_{72}$ et al (2013b); Chang et al (2013)), fewer studies have ${ }_{73}$ explored the STs in the SH.

While climate projections of a poleward shift of the ${ }_{75}$ SH storm track are well-know and accepted, simulations ${ }_{76}$ of the time scale of variability in the $\mathrm{SH}$ extratropical latitudes are still rather uncertain for the recent climate ${ }_{78}$ (Barnes and Polvani 2013), particularly in the summer ${ }_{79}$ season. Therefore, assessing GCMs with a recent reanal- ${ }_{80}$ ysis is a way to ensure they are accurately simulating ${ }_{81}$ the atmospheric circulation and the main climate pat- ${ }_{82}$ terns.

The most recent generation of GCMs used in the 84 Coupled Model Intercomparison Project (CMIP5, Tay- 85 lor et al (2012)) projects significant increase in the fre- 86 quency of extreme cyclones during the austral winter ${ }_{87}$ (Chang et al 2012; Chang 2017). In terms of the histori- 88 cal period, the CMIP5 simulations show a consistent $\mathrm{ST}_{89}$ seasonal cycle in relation to reanalysis, however weaker 90 and with an equatorward bias in their latitude (Chang ${ }_{91}$ et al 2012). Recent studies have suggested that the plan- ${ }_{92}$ etary wave feedbacks are not captured by the CMIP $5_{93}$ historical simulations, which impact the Southern An- 94 nular Mode (SAM) variability and, consequently, the ${ }_{95}$ storm tracks (Simpson et al 2013b). Chang (2017) have ${ }_{96}$ examined the CMIP5 results and found that GCMs un- ${ }_{97}$ derestimate the number of cyclones over the $\mathrm{SH}$ for $\mathrm{a}_{98}$ period between 1980-1999.

From a climate model perspective, while progressioo has been made in simulating the Northern Hemisphere101 (NH) ST features, few studies have explored the role of 102 the STs in the SH (IPCC 2013). Although relevant to this study in many aspects, different models and different analysis methods have been used in previous studies which can result in different results. In this paper the ability of a single model, the HadGEM2-ES, to represent the STs over the SH using a Lagrangian approach is assessed, which allow a more in depth analysis.

In this study the behaviour of the STs simulated by the HadGEM2-ES historical simulations, and their association with the large-scale circulation, are compared with the same diagnostics obtained from the ERA-Interim reanalysis for the period 1979-2005.

The paper continues in Section 2 with a description of the model and the diagnostic methodology; the results are presented in the Section 3; and the summary and conclusions are given in Section 4.

\section{Data and methodology}

\subsection{Model and Reanalysis data}

The HadGEM2-ES model is the second generation family of models of the United Kingdom Meteorological Office (UK - Met Office), created for the purpose of performing the Coupled Model Intercomparison Project Phase 5 (CMIP5) simulations (Jones et al 2011). The HadGEM2-ES is a coupled Atmospheric Ocean Global Circulation Model (AOGCM) where the atmospheric component has a resolution of N96 $\left(1.875^{\circ} \times 1.25^{\circ}\right)$ with 38 vertical levels (hybrid coordinate) and an ocean spatial resolution of $1.0^{\circ}$ with 40 vertical levels. The HadGEM2-ES timestep is 30 minutes for atmosphere/land and 1 hour for the ocean. The model also includes an interactive ocean and land carbon cycles and dynamic vegetation with an option to prescribe and simulate the $\mathrm{CO}_{2}$ concentrations (Martin et al 2011). An interactive tropospheric chemistry scheme is also included to simulate the interactions with atmospheric aerosols and the evolution of atmospheric composition (Bellouin and Collins 2011; Collins et al 2011).

The ensemble of HadGEM2-ES historical simulations consist of four model runs, generated from different initial conditions. Initial condition ensembles are required by the CMIP5 protocol in order to estimate if any apparent changes in climate may occur due to internal variability in the simulations. The initial conditions for individual ensemble members in the HadGEM2-ES historical simulations were selected using an objective method explained in Jones et al (2011). In this paper, the four ensemble members of the HadGEM2-ES historical simulations are hereafter referred to as HadGEM2ES. 
The second dataset used is the ERA-Interim reanal- 52 ysis (Dee et al 2011). This is used to provide verifica- 53 tion of the model results. The ERA-Interim reanalysis 54 uses the Cy31r2 version of the ECMWF atmospheric ${ }_{55}$ model that includes a revised cloud scheme, includ-56 ing treatment of ice supersaturation, implicit computa- 57 tion of convective transports, modified orographic drag, 58 salinity effect on saturation at ocean surface and gust 59 fix for orography. The data assimilation used is a $4 \mathrm{D}-60$ Variational data assimilation scheme (4D-Var) that includes a variational bias adjustment of the observations prior to assimilation (Dee et al 2011). These improve- 61 ments in the reanalysis system are important especially for the SH where the observations are less dense than ${ }^{62}$ in the NH, particularly the terrestrial observations.

\subsection{Cyclone feature tracking}

Cyclones are identified and tracked using the tracking ${ }_{68}^{67}$ scheme of Hodges $(1994,1995,1999)$. This allows the ${ }_{69}$ construction and analysis of the climatology, variability and properties of weather systems such as extratropical ${ }_{71}^{70}$ cyclones (Hoskins and Hodges 2002; Hodges et al 2003; Hoskins and Hodges 2005; Hodges et al 2011).

The tracking is applied to 6 hourly relative vorticity ${ }_{74}^{73}$ at $850 \mathrm{hPa}$ to identify the cyclones. The benefits of using ${ }_{75}$ the relative vorticity are that it focuses on smaller spa- ${ }_{76}$ tial scales than other fields, however, it is a noisy field. Hence the vorticity is spectrally filtered by truncation to T42 and the large-scale background is removed for ${ }_{79}$ total wavenumbers $<=5$. Cyclones are initially identi- ${ }_{80}$ fied as minima in the filtered vorticity field, for the $\mathrm{SH},{ }_{81}^{80}$ and then refined by determining the off-grid locations ${ }_{82}$ using B-spline interpolation and steepest descent mini- ${ }_{83}$ mization, this produces smoother tracks. The tracking ${ }_{84}$ is performed directly on the sphere to exclude biases ${ }_{85}$ that can occur when using projections. Tracks are ini- ${ }_{86}$ tialised using a nearest neighbour method and then re- ${ }_{87}$ fined by minimising a cost function for track smooth- ${ }_{88}$ ness subject to constraints on displacement distance in ${ }_{89}^{88}$ a time step and the track smoothness. This is the same methodology as previously used by Hoskins and Hodges ${ }_{91}$ (2002). On completion of the tracking the tracks are fil- ${ }_{92}$ tered to retain only the mobile systems that last at least ${ }_{93}$ 2 days (8 time steps) and travel further than $1000 \mathrm{~km}$. Spatial statistics are computed using the spherical kernel method (Hodges 1996). The main advantage of this ${ }_{94}$ statistical method is that the statistics are computed directly on the sphere, which reduces the biases that ${ }_{95}$ can occur if computing the statistics on a projection 96 using grid boxes.

The track diagnostics consist of the cyclone counts, 97 track, genesis and lysis densities and the mean growth 98 and decay rates. The densities indicate the spatial distribution of the cyclones and are scaled to number density per month per unit area, where the unit area is $5^{\circ}$ spherical cap $\left(\approx 10^{6} \mathrm{~km}^{2}\right)$. The tracking and statistics are computed for the seasonal periods of December to February (DJF), March to May (MAM), June to August (JJA) and September to November (SON), but in this paper only the austral winter (JJA) and summer (DJF) are considered.

\subsection{Large-scale analysis}

The large-scale fields are explored to investigate their relationship with the cyclone statistics. Diagnostic fields have been calculated using monthly means from the HadGEM2-ES ensemble members and ERA-Interim data for $500 \mathrm{hPa}$ geopotential height anomaly; baroclinicity; and sectorial zonal means of the zonal component of wind and temperature, as described below.

The $500 \mathrm{hPa}$ mean geopotential height anomaly is calculated by first subtracting the zonal mean from the full $500 \mathrm{hPa}$ geopotential height field for each month and then averaging over all months for each season. The geopotential anomalies will be used to explore the stationary wave patterns.

The baroclinicity is computed as the Eady growth rate (Eady 1949) by month and analyzed at the $850 \mathrm{hPa}$ and $250 \mathrm{hPa}$ levels. The adjacent levels used in the calculation of the vertical gradients are the $925 \mathrm{hPa}$ and $700 \mathrm{hPa}$, and $300 \mathrm{hPa}$ and $200 \mathrm{hPa}$, respectively. This analysis will be used to show an energetic perspective of the STs.

The sectorial zonal means of the zonal wind and temperature have been calculated for latitudes between $90^{\circ} \mathrm{S}$ and $0^{\circ}$ for longitudes between $60^{\circ} \mathrm{W}$ and $20^{\circ} \mathrm{E}$, $35^{\circ} \mathrm{E}$ and $130^{\circ} \mathrm{E}$, and $150^{\circ} \mathrm{E}$ and $75^{\circ} \mathrm{W}$, which represent the Atlantic, Indian and Pacific Oceans, respectively. These sectors were chosen with a focus on the circulation over the major water masses and, in the case of the Atlantic sector, to capture circulation changes and biases leeward of the Andes Mountains - South America (SA)- to Cape Agulhas - South Africa. These diagnostic fields will be used to show a vertical perspective of the STs.

\section{Results}

3.1 Climatology, bias and differences in spatial distribution

As a background for the discussion, Figures 1 and 2 shows the cyclone density statistics for the winter and 
Table 1 Number of cyclones per month for the winter and 36 summer seasons that are found in the Southern Hemisphere ${ }_{37}$ extratropics, $\left(90^{\circ} \mathrm{S}, 20^{\circ} \mathrm{S}\right)$ for the period 1979-2005. Abbreviations: EM, Ensemble Member.

\begin{tabular}{lll}
\hline Experiment & JJA & DJF \\
\hline HadGEM2-ES EM 1 & 130.7 & 109.0 \\
HadGEM2-ES EM 2 & 131.4 & 108.4 \\
HadGEM2-ES EM 3 & 131.5 & 108.8 \\
HadGEM2-ES EM 4 & 130.7 & 108.1 \\
& & \\
\hline HadGEM2-ES & 131.1 & 108.6 \\
ERA-Interim & 134.0 & 111.9 \\
Differences & -2.9 & -3.3 \\
\hline
\end{tabular}

main characteristic of the ST is the spiral from South America, around Antarctic, through the Atlantic and Indian Oceans, and to the Antarctic Peninsula (Fyfe 2003; Hoskins and Hodges 2005). The largest track density region can be seen around the Antarctic coast between $120^{\circ} \mathrm{E}$, and $80^{\circ} \mathrm{W}$ due to secondary development around the Antarctic coast associated with decaying systems moving in from lower latitudes. The lowest track densities tend to be found to the south of New Zealand and are most apparent in the winter, and are related to the presence of Rossby wave sources in the Indian Ocean (Inatsu and Hoskins 2006).

The winter storm track density biases are shown in Figure 1c. The model (Fig. 1a) overestimates the cyclone density near to southern Australia and underestimates the cyclones density around the coast of Antarctica. This reveals that the HadGEM2-ES model does not represent well the climatological track spiral (Hodges et al 2011) over these regions, as shown in Figures 1a and $b$. In the region between the Indian and Pacific Ocean, near to $45^{\circ} \mathrm{S}$ and $120^{\circ} \mathrm{E}$, positive biases are associated with the presence of more cyclones in HadGEM2ES. These positive biases occur because the ST is too zonal due to fewer cyclones that move polewards. Similar results were found using older generations of models, such as the ECHAM5 climate model (Bengtsson et al 2006). This insufficient poleward motion is associated with the wrong representation of the stationary wave pattern (Fig. 6a). In addition, large temperature biases between the Antarctic and the Equator regions (Fig. 5, left column) contribute to enhance local baroclinicity (Fig. 3a and b) (as will be discussed further in Section 3.2.1).

The genesis density climatology during the austral winter is shown in Figure 1d for ERA-Interim. In general cyclogenesis occurs throughout the main ST region due to secondary cyclogenesis and downstream development (Chang 1993; Inatsu and Hoskins 2004; Hoskins and Hodges 2005; Hodges et al 2011). More concentrated cyclogenesis occurs in two well-known regions in the southeast of SA, specifically leeward of the natural barrier of the Andes Mountains, one stronger in the northeast of Argentina related to the Subtropical Jet and mountain effect, where strong but shallow cyclonic systems on the subtropical jet cross the Andes (Hoskins and Hodges 2005), and the other in the extreme south of SA, which is related to where the ST from the Pacific Ocean crosses the mountains enhanced by oceancontinent temperature contrast (Gan and Rao 1991, 1994, 1996; Hoskins and Hodges 2005; Reboita et al 2010). Other major genesis density maxima are found on the Antarctic coast, the first with center at $65^{\circ} \mathrm{S}$ e $165^{\circ} \mathrm{E}$ and a second near to Drake Passage, with both
The storm track density climatology during the winter 87 season is presented in Figure 1b for ERA-Interim. The 88 

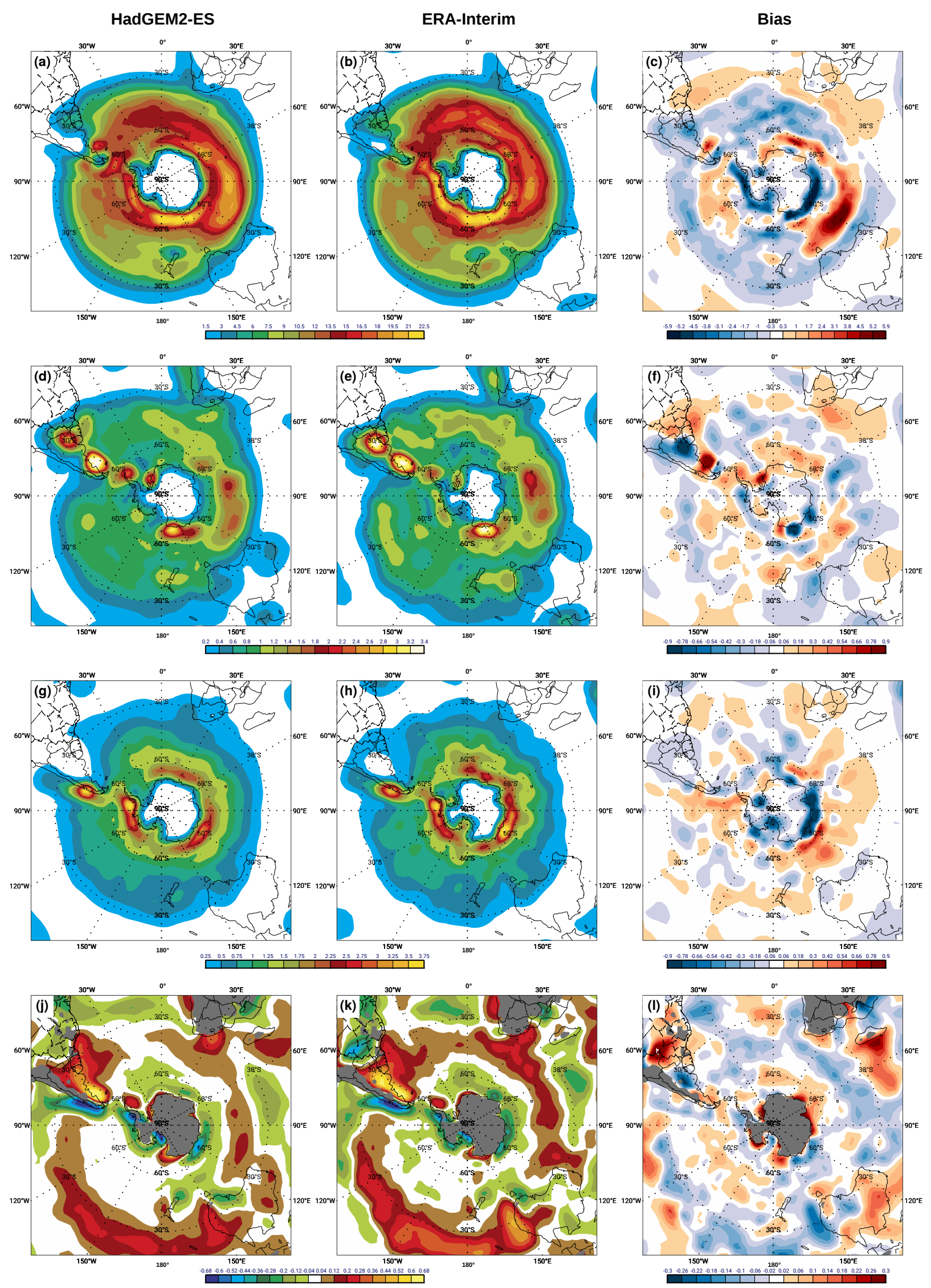

Fig. 1 Extratropical cyclone climatology based on the HadGEM2-ES (left column), ERA-Interim reanalysis (middle column) and their differences (HadGEM2-ES minus ERA-Interim, right column) in JJA for 1979-2005 over Southern Hemisphere: (a), (b) and (c) Track Density; (d), (e) and (f) Genesis Density; (g), (h) and (i) Lysis Density; and (j), (k) and (l) Mean Growth Decay Rate. Densities are in units of number density per month per unit area $\left(\approx 10^{6} \mathrm{~km}^{2}\right)$. For figures $(\mathrm{j})$, (k) and (l) locations where orography is above $850 \mathrm{hPa}$ are shaded with grey color. 
1 associated with upstream decay and lysis (Figs. 1h and 53 $\mathrm{k}$ ), which enhances the local baroclinicity resulting in ${ }_{54}$ reinvigoration or secondary cyclogenesis. Another cy- 55 clogenesis region can be seen close to the Australian 56 coast, also found by Hoskins and Hodges (2005), and is 57 related to the winter split jet. The region between $20^{\circ} \mathrm{S}_{58}$ and $50^{\circ} \mathrm{S}$ is dominated by cyclone growth rates (Fig. 59 $1 \mathrm{k}$, positive values) where the maximum can be seen 60 on the east side of Andes Mountains.

The winter cyclogenesis biases are shown in Figure ${ }^{62}$ 1f. Two strong biases regions are seen over the south ${ }^{63}$ of SA during the winter and both occur due to mag- ${ }^{64}$ nitude, size and position differences of the cyclogenetic ${ }^{65}$ regions between the model and the reanalysis. The neg- ${ }^{66}$ ative bias over Northeast Argentina and Uruguay oc- ${ }^{67}$ curs because HadGEM2-ES represents the location of ${ }^{68}$ the cyclogenesis well (Figs. $2 \mathrm{~d}$ and e), but with lower ${ }^{69}$ density and also extends further into the Southern Atlantic Ocean. On the other hand, in the centre-south 70 region of Argentina a positive bias can be seen which is more related to a difference in location rather than 71 differences in magnitude. Further south, between $50^{\circ} \mathrm{S} 72$ and $70^{\circ} \mathrm{S}$, there is another concentrated genesis/lysis 73 biases associated with the peak of cyclogenesis (Figs. 74 $1 \mathrm{~d}$ and e) and lysis/decay (Figs. $1 \mathrm{~h}$ and $\mathrm{k}$ and Figs. $1 \mathrm{~g} 75$ and $\mathrm{j}$ ), that results in differences associated with loca- 76 tion in both fields (Figs. 1i and 1). Negative biases are 77 also seen around Antarctic (Fig. 1f). The biases seen 78 in the SA (Fig. 1f) may be related to the model spa- 79 tial resolution, which can impact the representation of 80 the orography and cyclone diabatic processes especially 81 when the cyclones cross the Andes Mountains.

Further genesis biases (Fig. 1f) can be seen over the ${ }^{83}$ southeast of Brazil and South Africa associated with ${ }^{84}$ stronger cyclone growth in the HadGEM2-ES model ${ }^{85}$ (Fig. 11). Positive biases can also be seen near to the ${ }^{86}$ south coast of Australia indicating that the model rep- ${ }^{87}$ resents more cyclogenesis (Fig. 1d) in this region al- ${ }^{88}$ though the low track densities are well represented mainly over New Zealand.

Finally, the lysis density climatology is presented in 92 Figure $1 \mathrm{~h}$ for ERA-Interim. The cyclolysis maximum 93 regions are concentrated around the Antarctic coast, 94 with a maximum near to the Antarctic Peninsula and 95 another at the same longitude of Australia. Also, an 96 important region can be seen on the windward side of 97 South America related to where the ST intercepts the 98 Andes Mountains, causing lysis on the upslope. The 99 cyclone decay rate regions (Fig. 1k, negative values) ${ }_{100}$ are seen in tropical and high latitudes around the $\mathrm{SH}_{, 101}$ with a maximum close to the Andes Mountains and102 Antarctic coast.
For cyclolysis (Fig. 1i) there are negative biases around Antarctic, which are related to the incorrect simulation of the spiral of activity towards the Antarctic coast. On the other hand, a positive bias is found between the south of SA and the Antarctic Peninsula related to the larger decay rate found in HadGEM2-ES (Fig. 1j). The results found for the cyclone growth/decay rate biases (Fig. 11) are related to the same spiral pattern. The problem to represent the spiral pattern toward Antarctic during the winter is directly associated with the track and genesis underestimation leeward of the mountains, indicating that the cyclones are not well represented in the Andes Mountains region. Previous studies such as Tamarin and Kaspi (2017) show that the stationary wave pattern is opposing the transient nonlinear advection and latent heat release, thus the poleward tendency of the storms is reduced.

\subsubsection{Summer}

The track density climatology for the austral summer is shown in Figure 2b for ERA-Interim. The main characteristics of the STs are that they are narrower, more zonal and symmetric than in the winter season. These differences are associated mainly with a single eddydriven jet (Fig. 7, right column), in contrast with the split jet during the winter (Fig. 5, right column), and also with cyclonic systems at high levels, such as cold vortices, that are less intense and in general have trajectories over regions of higher latitudes (not shown). The track density maximum is located between SA and the Antarctic Peninsula (Fig. 2b), which is related to the single eddy-driven jet over the South Pacific Ocean and the orography of the Andes Mountains that tends divert it to south.

The cyclone track density differences between HadGEM2ES and ERA-Interim in the summer season are shown in Figure 2c, and show relatively small magnitudes of bias possibly because the storm track is more zonal than in the winter (Figs. 2a and b). In summary, the summer storm tracks are more concentrated between the latitudes $50^{\circ} \mathrm{S}$ and $60^{\circ} \mathrm{S}$ with the exception of the Atlantic Ocean that is slightly wider near to SA.

The track density differences (Fig. 2c) are slightly smaller than winter though the distribution is more concentrated. The main differences can be seen around the Antarctic and at equatorward latitudes. In the Pacific Ocean can be seen biases around the Antarctic coast and a larger positive bias towards New Zealand (Fig. 2c), which is explained by fewer cyclones that move from the South Australia coast and Tasman Sea in comparison with ERA-Interim (Figs. 2a and b). The bias magnitudes are similar to the winter season in this re- 

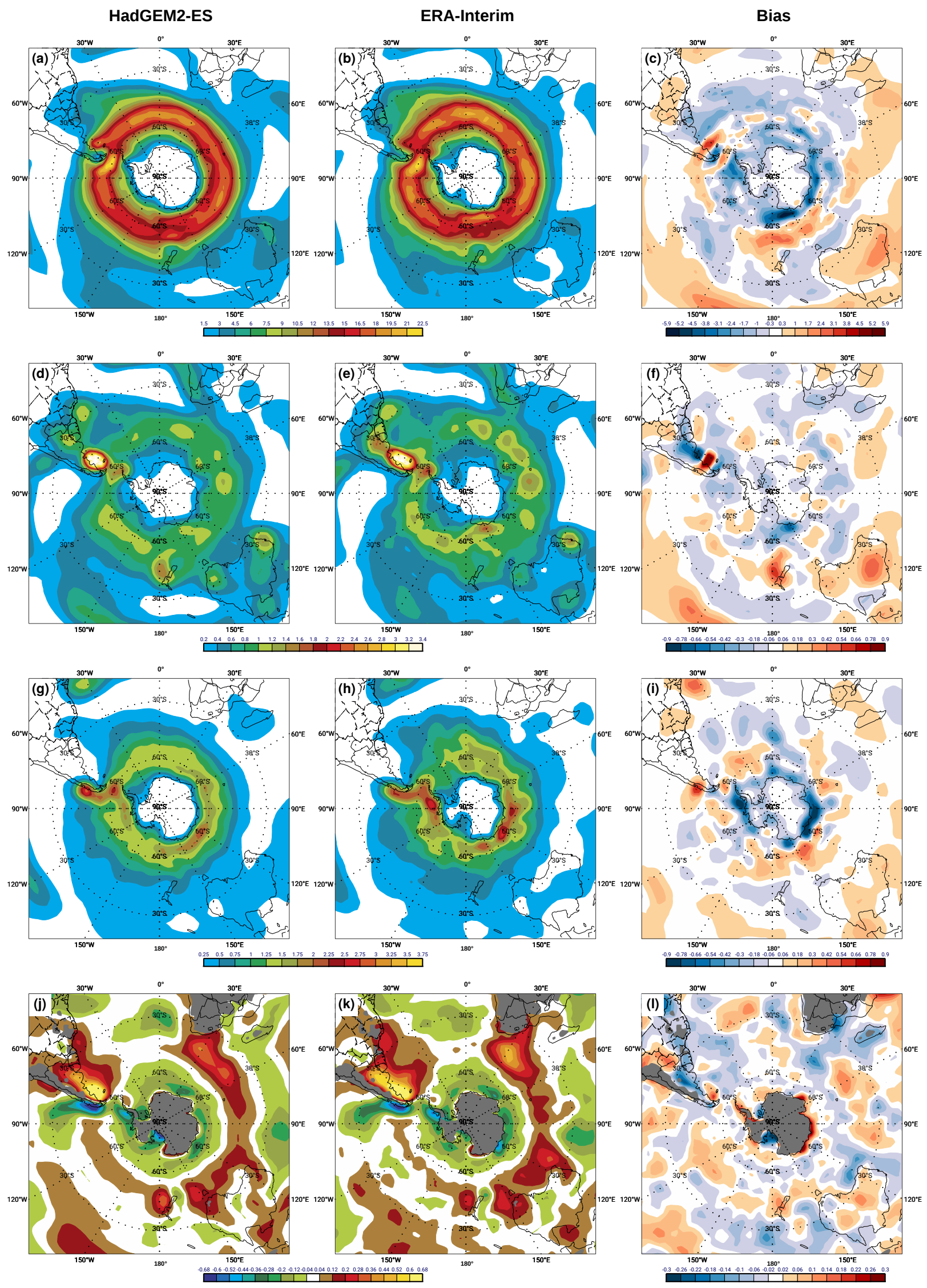

Fig. 2 As in Figure 1 but for the Summer (DJF). 

gion. In the Atlantic sector the storm tracks have simi- 54 lar bias magnitudes to the winter season, with the main 55 biases close to SA (Fig. 2c). In summer, according to 56 the climatology, cyclones tend to cross the Andes Moun- 57 tains slightly to the north which can reduce the model ${ }_{58}$ overestimation of tracks in this region. HadGEM2-ES 59 tends to represent more cyclones on the equatorward 60 flank of the ST over the Indian and Pacific Oceans (Fig. 61 2a).

Figure 2e show the regions of cyclogenesis in the 63 SH for ERA-Interim during the summer season. The 64 two main peaks of genesis density can be seen over Ar- 65 gentina on the eastern side of the Andes Mountains, one 60 stronger to the south that occurs mainly due to the jet 67 stream moving to a more poleward position during the 68 summer and the other to the northeast, both are also 69 related to mountain effects (Hoskins and Hodges 2005). 70

Other regions of cyclogenesis are seen near the south- ${ }^{71}$ east of Brazil around $25^{\circ} \mathrm{S}$ (Fig. 2e), which generate ${ }^{72}$ cyclones different from those of the classical model of ${ }^{73}$ Bjerknes and Solberg (1922) and the cyclones have sub- ${ }^{74}$ tropical features (Evans and Braun 2012). Cyclone for- ${ }^{75}$ mation in this region has the same mechanisms as win- 76 ter, however weaker due to the poleward jet stream po- ${ }^{77}$ sition. This condition is enhanced by land-ocean tem- ${ }^{78}$ perature contrasts (Gan and Rao 1991), the low-level ${ }^{79}$ jet east of the Andes (Marengo et al 2004), and mois-80 ture advection from northern Brazil associated with the ${ }^{81}$ upper-level circulation, such as a low over northeast of ${ }^{82}$ Brazil and a high over Bolivia and the centre of Brazil. ${ }^{83}$ These conditions favour cyclogenesis and make the cy- ${ }^{84}$ clones move poleward and eastward along the southern ${ }^{85}$ edge of the South Atlantic Convergence Zone (SACZ) ${ }^{86}$ cloud band (Taljaard 1972; Hoskins and Hodges 2005). ${ }^{87}$ Similarly, a genesis region can be seen around $150^{\circ} \mathrm{W}^{88}$ along the southern edge of the South Pacific conver- ${ }^{89}$ gence zone (SPCZ) (Fig. 2e). There are other cyclo- ${ }^{90}$ genesis maxima on the Antarctic Peninsula (Fig. 2e), ${ }^{91}$ that are weaker than winter, near to Western Australia ${ }^{92}$ and over the Atlantic, Pacific and Indian Oceans due ${ }^{93}$ to weak westward-moving tropical systems as also de- ${ }^{94}$ scribed in Hoskins and Hodges (2005).

The summer cyclone growth rate climatology (Fig. ${ }^{96}$ $2 \mathrm{k}$, positive values) is, in general, smaller than winter ${ }^{97}$ with the peak areas found near to cyclogenesis areas. However, over the cyclogenesis regions close to South ${ }_{98}$ Africa, the growth rates are larger than in the winter (Fig. 2k).

Figure 2f shows the summer genesis density differ-100 ences, this indicates a negative bias over the Northeastion of Argentina, Uruguay and the extreme south of $\mathrm{SA}_{102}$ though the model represents the position of this cyclo-103 genesis well. The other two cyclogenesis regions, in thero4 southeast of Brazil and south of Argentina, show that the model (Fig. 2d) represents the position and magnitude of these well, however with some small differences (Fig. 2f).

For other cyclogenesis regions (Fig. 2f), the HadGEM2ES has a good representation of the position of the cyclogenesis around the Australian coast although with larger values than climatology (Figs. 2d and e). In these regions, the model also tends to underestimate the growth rate as shown in Figure 2d. As discussed before, this pattern is related to the zonal temperature differences that will be discussed further in Section 3.2.2.

Finally, the lysis density climatology is shown in Figure $2 \mathrm{~h}$ for ERA-Interim. Generally, the lysis pattern in the summer is similar to the winter season with a slightly reduced maxima in the main regions near to Antarctic. The cyclolysis peak over South America in this season is shifted slightly to the south and with smaller magnitude in comparison to the winter season. Other lysis peaks can be seen in the Eastern Northeast of Brazil related to the propagation of Easterly Wave Disturbances (Gomes et al 2015). During the summer season the mean decay rates (Fig. $2 \mathrm{k}$, negative values) are qualitatively similar in most parts of the SH, however with a smaller maximum rate. In comparison with winter (Fig. 1k, negative values), the decrease of the decay rate can be seen in the Andes Mountains that is slightly moved to the south (Fig. $2 \mathrm{k}$, negative values).

The lysis density biases for the summer season are shown in Figure 2i. The results indicate that the main negative biases occur in the Indian Ocean, near to Antarctica, and over the Antarctic Peninsula. A positive bias can be seen to the west of the Andes Mountains and over the Drake Passage. As discussed before, these patterns are associated with the track distribution narrowing and with the difficulty of the model (Fig. $2 g$ and j) to represent the cyclones that cross the Andes Mountains (mountain effect and lysis/decay rate on the upslope, Section 3.1.1). This indicates that HadGEM2-ES tends to reduce the cyclones before and underestimate them after the Andes Mountains for the cyclogenesis region over south of SA (Figs. 2j), which can also be explained by the cyclone decay rate negative bias in the Figure 21 .

\subsection{Large-scale bias}

Before presenting the large-scale bias results comparing the mean flow, the biases of the baroclinicity at the upper level of $250 \mathrm{hPa}$ (Figs. 3a and c), and the lower level of $850 \mathrm{hPa}$ (Figs. $3 \mathrm{~b}$ and d) are shown for the HadGEM2-ES relative to ERA-Interim and the ERAInterim climatology (black dashed contours) to pro- 
1 vide a frame of reference. The baroclinicity represents 51 a measure of how favorable the environment is for the ${ }_{52}$ growth of cyclones in extratropical regions. In this way, 53 it is possible to link regions of cyclogenesis and cyclone 54 growth rate with the large-scale environment.

The ERA-Interim climatology (Figs. 3a and b, black 56 dashed contours) shows that the baroclinicity is largest 57 in the winter season when contrasted with summer at 58 both levels, shown in Figures 3c and d, with peak val-59 ues found in the vicinity of the subtropical jet. Also 60 seen are strong values around Antarctic that are linked 61 to the strong polar vortex during the austral winter. 62 The strong values found in the vicinity of the Madagas- 63 car Island, South coast of Australia and South America 64 correspond with the climatological cyclogenesis and cy- ${ }_{65}$ clolysis features. The spiral pattern found in the track ${ }_{66}$ density is also seen in the latitude of maximum Eady ${ }_{67}$ growth rate at $850 \mathrm{hPa}$ (Fig. $3 \mathrm{~b}$ ), which is largest in the ${ }_{68}$ vicinity of the SH ST. The winter bias (Figs. 3a and b) ${ }_{69}$ indicates the model tends to underestimate the baro- ${ }_{70}$ clinicity in the subtropical jet over all the $\mathrm{SH}$, on the ${ }_{71}$ other hand, there is an overestimate at the latitudes of ${ }_{72}$ the polar jet. These results will be discussed further in ${ }_{73}$ Section 3.2.1.

The summer baroclinicity is shown in Figures $3 \mathrm{c}_{75}$ and d (black dashed contours). In this season the baro- 76 clinicity is more zonally symmetric and weaker than 77 winter at both levels with some cyclone ST features, 78 such as track and genesis maxima, can also be found 79 close to the baroclinicity peaks. Strong baroclinicity is 80 found in the southeast of SA, south of South Africa and 81 in the region that extends from Australia towards New 82 Zealand. Although the main patterns are well repre- 83 sented, the HadGEM2-ES tends to underestimate the 84 baroclinicity in these main regions, as shown in Fig- 85 ure $3 \mathrm{c}$. The positive summer biases at $250 \mathrm{hPa}$ (Fig. 3c) 86 indicate that the model simulates the jet stream inten- 87 sity stronger than reanalysis in the $\mathrm{SH}$, which can be 88 related to the narrowing of the storm tracks (as will be 89 discussed further in Section 3.2.2).

During the winter season the jets are split with the polar jet between $60^{\circ} \mathrm{S}$ and $40^{\circ} \mathrm{S}$, and the subtropical jet, $30^{\circ} \mathrm{S}$ and $20^{\circ} \mathrm{S}$, as shown in the Figure 5 (black lines contour) for Atlantic (b), Indian (d) and Pacific (f) Oceans. HadGEM2-ES tends to show lower wind speeds associated with the eddy-driven jet, however the subtropical jet has positive speed biases and is further equatorward in relation to the climatological position. These biases corresponds with the strong positive baroclinicity bias at $250 \mathrm{hPa}$ (Fig. 3a). Over the Indian Ocean towards New Zealand they are related to the poor representation of the winter split jet typical in climate models (Bengtsson et al 2006; Simpson et al 2013a).

The zonal mean temperature biases are shown for the Atlantic (Fig. 5a), Indian (Fig. 5c) and Pacific (Fig. 5e) Oceans. The model indicates negative biases in all oceans basins from the high-middle troposphere levels at the pole towards lower levels in tropical regions. The peak negative biases are found at upper levels (300$100 \mathrm{hPa}$ ) in latitudes between $60^{\circ} \mathrm{S}$ to $40^{\circ} \mathrm{S}$, which are associated with the displaced representation of the polar jet at upper levels in the HadGEM2-ES over the southern oceans. On the other hand, positive maxima can be seen in the Indian Ocean (Fig. 5c) near to the pole that extends from lower to middle levels, which indicates that the HadGEM2-ES tends to overestimate the temperature in the Antarctic region. Previous studies such as Jones and Harpham (2013) found that temperature biases are largest at polar latitudes in the ERA-Interim reanalysis mainly in the autumn and winter seasons, which is much colder than direct estimates. This indicates that biases could be larger than shown in Figure 5c. These patterns, associated with the split jet speed bias and the bias in the spiral representation of the ST in the model, corresponds with the Eady growth negative bias observed around the Antarctic, and the positive bias observed in the Indian Ocean between the latitudes of $40^{\circ} \mathrm{S}$ and $30^{\circ} \mathrm{S}$.

Previous studies such as that of Taljaard (1972); Rao et al (2002); Hoskins and Hodges (2005); Inatsu and Hoskins (2006); Woollings (2010), show that the jets commonly split in the time mean in this region and act as two waveguides for most of the time, which create two branches of the storm tracks over the $\mathrm{SH}$ (Berbery and Vera 1996; Chang 1999; Rao et al 2002; Nakamura and Shimpo 2004; Inatsu and Hoskins 2006). Inatsu and Hoskins (2006) show that the split jet occurs due to propagation of Rossby Waves associated with the cross equatorial flow and the monsoon in the subtropical Indian Ocean. Also, Hoskins and Ambrizzi (1993) show that a slower jet can reduce the meridional shear which results in a less poleward waveguide, which 

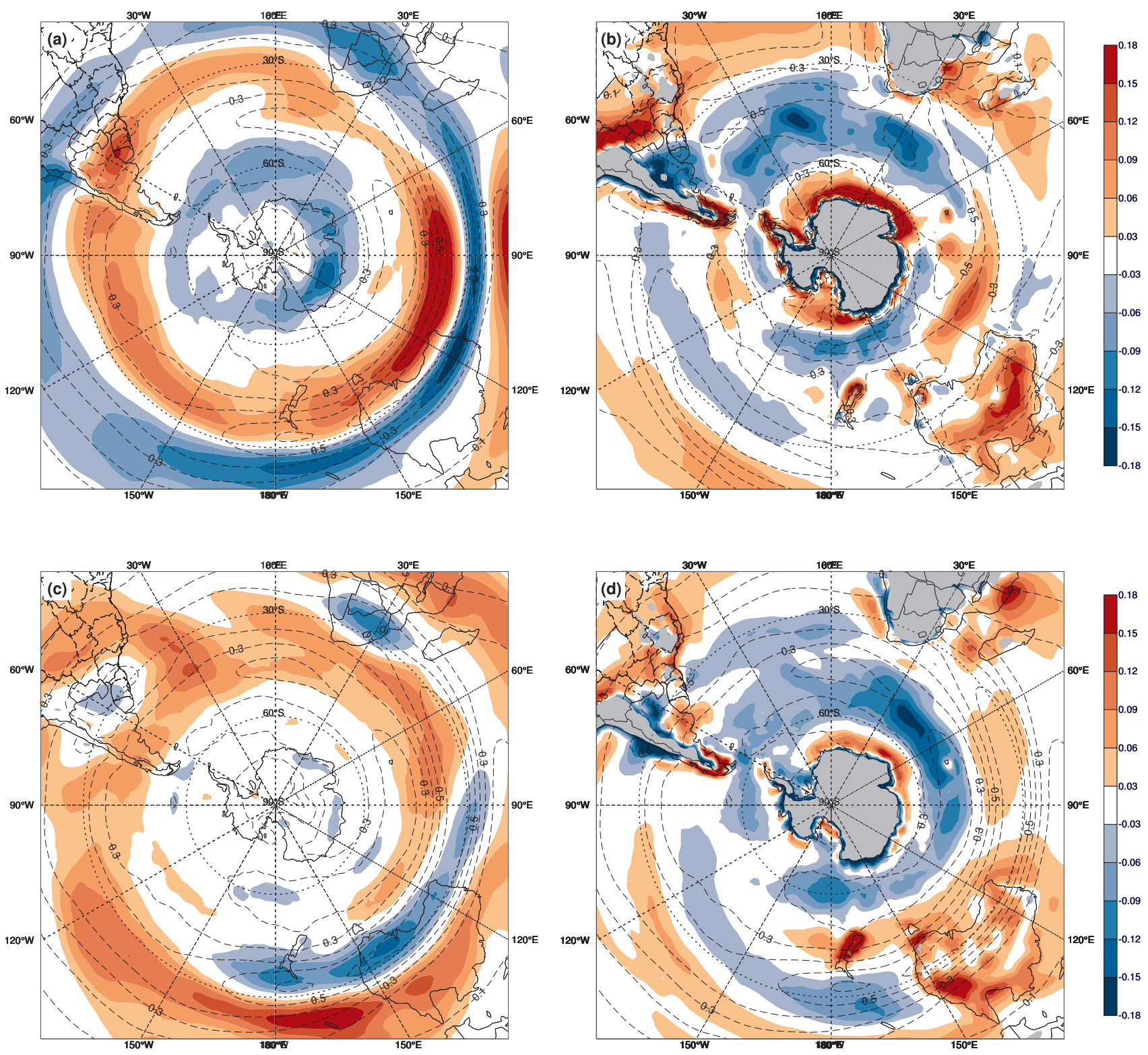

Fig. 3 Maximum Eady growth rate $\left(d_{a y}{ }^{-1}\right)$ biases (HadGEM2-ES minus ERA-Interim) at 250hPa (left column) and 850hPa (right column) for the Southern Hemisphere: (a) and (b) winter; (c) and (d) summer. Black dashed contours show ERA-Interim climatology for the period 1979-2005. The locations where orography is above $850 \mathrm{hPa}$ are shaded with grey color.

could contribute in HadGEM2-ES (Fig. 5b, d and f) to 12 more dissipation at the poles and more waves propagat- 13 ing out of the jet towards tropical latitudes. The com- 14 bination of these factors associated with track density 15 biases (Fig. 1c) indicate that HadGEM2-ES does not ${ }_{16}$ represent the jet spatial and seasonal variability well, such that more biases occur in this region and extend through out the Pacific and Atlantic Oceans.

The slower and equatorward shift of the eddy-driven 20 jet and track density biases are supportive of the hy- 21 pothesis that HadGEM2-ES does not simulate the Rossbyx
Wave trains correctly. To test this hypothesis, the sea surface temperatures (SST) and $500 \mathrm{hPa}$ geopotential height zonal anomaly were investigated to indicate biases that can affect directly the stationary wave patterns.

Figure 4a shows SST positive biases in extratropical latitudes over the Atlantic towards the Indian Ocean which corresponds with the positive geopotential anomaly biases (Fig. 6a) over this region during the winter. The SST biases may be related to problems in the climate model physics to represent cloud feedbacks (Lin et al 

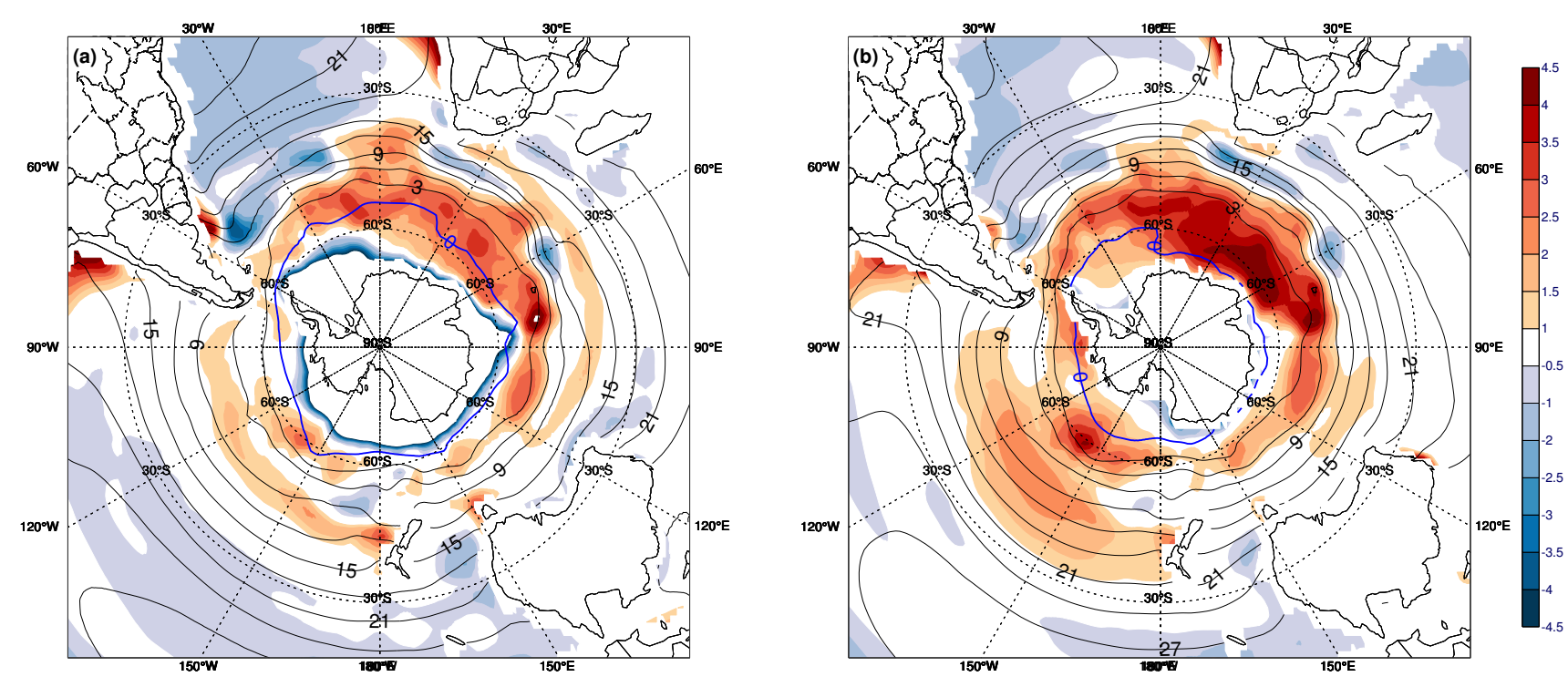

Fig. 4 Sea surface temperature $\left({ }^{\circ} \mathrm{C}\right.$ ) biases (HadGEM2-ES minus ERA-Interim) for (a) JJA and (b) DJF. Black line contours show ERA-Interim climatology for the period 1979-2005 and blue line contour indicate $0^{\circ} \mathrm{C}$.

2014). This seems to indicate that the SSTs contribute 32 to a change in the Rossby Wave trains, which results in ${ }_{33}$ a change in the location of the centres of geopotential ${ }_{34}$ anomalies (Fig. 6a) and consequently of the waveguides 35 over the southern oceans (Inatsu et al 2002; Bengtsson 36 et al 2006). Kidston and Vallis (2012) have discussed ${ }_{37}$ the relationship between the speed and the latitude of ${ }_{38}$ an eddy-driven jet in a simple barotropic model. They $з 9$ found that when the wind speed is increased the jet 40 shifts poleward because of increase of the meridional ${ }_{41}$ shear and reduces the absolute vorticity gradient on ${ }_{42}$ the flanks of the jet. Therefore, the results found agree ${ }_{43}$ with those of Kidston and Vallis (2012) that a slower 44 jet reduces the meridional shear so that the waveguide ${ }_{45}$ becomes less poleward with an increase in waves prop- ${ }_{46}$ agating out of the jet increasing the poleward dissipa- ${ }_{47}$ tion, resulting in an equatorward shift.

The $500 \mathrm{hPa}$ geopotential height zonal anomaly bi- 49 ases and ERA-Interim geopotential height climatology 50 (black lines) are shown in Figure 6 for austral winter (a) ${ }^{51}$ and summer (b). During the winter (Fig. 6a) the neg-52 ative biases between latitudes of $40^{\circ} \mathrm{S}$ and $20^{\circ} \mathrm{S}$ in the ${ }^{53}$ Atlantic Ocean are related to the representation of the ${ }^{54}$ cyclogenesis over the northeast of Argentina/Uruguay ${ }^{55}$ which are slightly displaced to the adjacent ocean (Figs. 56 $1 d$, e and f) and consequently with more cyclones that ${ }_{57}$ propagate toward Africa. Although the model shows 58 more baroclinicity at the $250 \mathrm{hPa}$ level (Fig. 3a) and 59 less geopotential height (Fig. 6a), this storm track pat- 60 tern is observed mainly above $30^{\circ} \mathrm{S}$ (Fig. 1a). Other ${ }_{61}$ negative biases (Fig. 6a) are observed at extratropical ${ }_{62}$ latitudes, one in the Indian Ocean $\left(80^{\circ} \mathrm{E}\right.$ and $\left.150^{\circ} \mathrm{E}\right)$ that corresponds with the track density positive bias peaks (Fig. 1c) and the model reduced spiral toward the Antarctic in relation to ERA-Interim climatology (Figs. 1a and b), and the other in the Pacific Ocean $\left(140^{\circ} \mathrm{W}\right.$ and $\left.80^{\circ} \mathrm{W}\right)$, where a positive biases in track density is seen (Fig. 1c). However, the geopotential positive biases (Fig. 6a) are also found in the three ocean basins, where the maximum is over extratropical region between $40^{\circ} \mathrm{W}$ and $60^{\circ} \mathrm{E}$, near to south of South Africa. This region has two common problems seen in climate models, the ocean currents and the sea surface temperature (Woollings et al 2010).

According to O'Reilly and Czaja (2015) in the North Pacific Ocean there is a relation between the ocean fronts and the downstream dynamics. In this way, they suggest there may be a similar pattern over the South Atlantic, with the Agulhas Front having a direct relation with the interaction between the variability of the Agulhas Current and the downstream dynamics, thus influencing the lower level baroclinicity. This relation was also found by Nakamura (2012). The poor representation in the models, associated with the SST biases (Fig. 4a), may contribute to the strong storm track biases found in the Indian Ocean.

Continuing the discussion of Figure 6a, two other positive biases are found in the Pacific Ocean, one near to New Zealand towards Antarctic and the other close to South America, and these stationary wave patterns contribute to the track density negative biases (Fig. 1c) observed over these regions. 

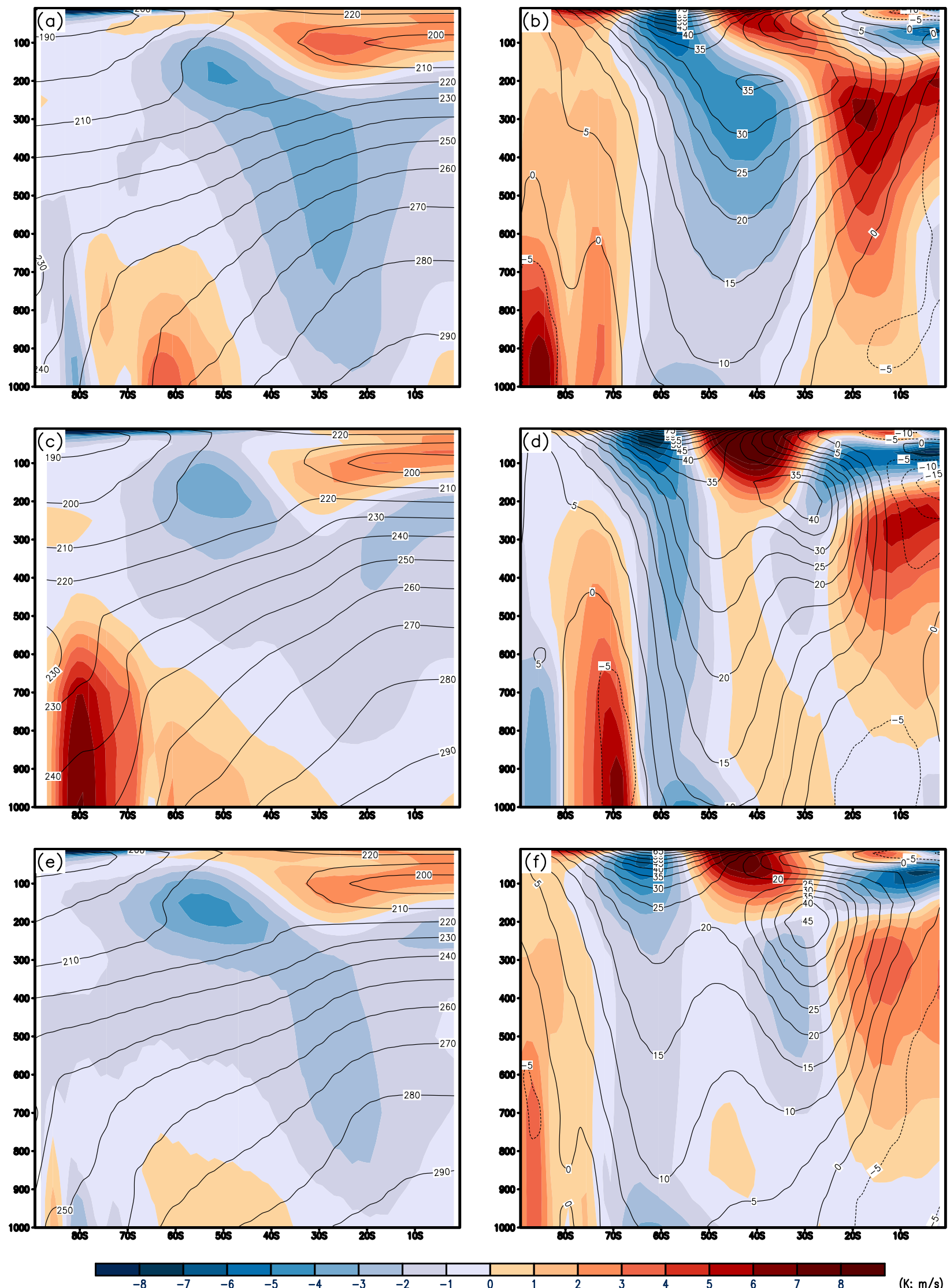

Fig. 5 Zonal mean temperature (K) (left column) and zonal mean zonal wind $(\mathrm{m} / \mathrm{s}$ ) (right column) biases (HadGEM2-ES minus ERA-Interim) in JJA for the Southern Hemisphere Oceans: (a) and (b) Atlantic; (c) and (d) Indian; and (e) and (f) Pacific. Black line contours show ERA-Interim climatology for the period 1979-2005. 

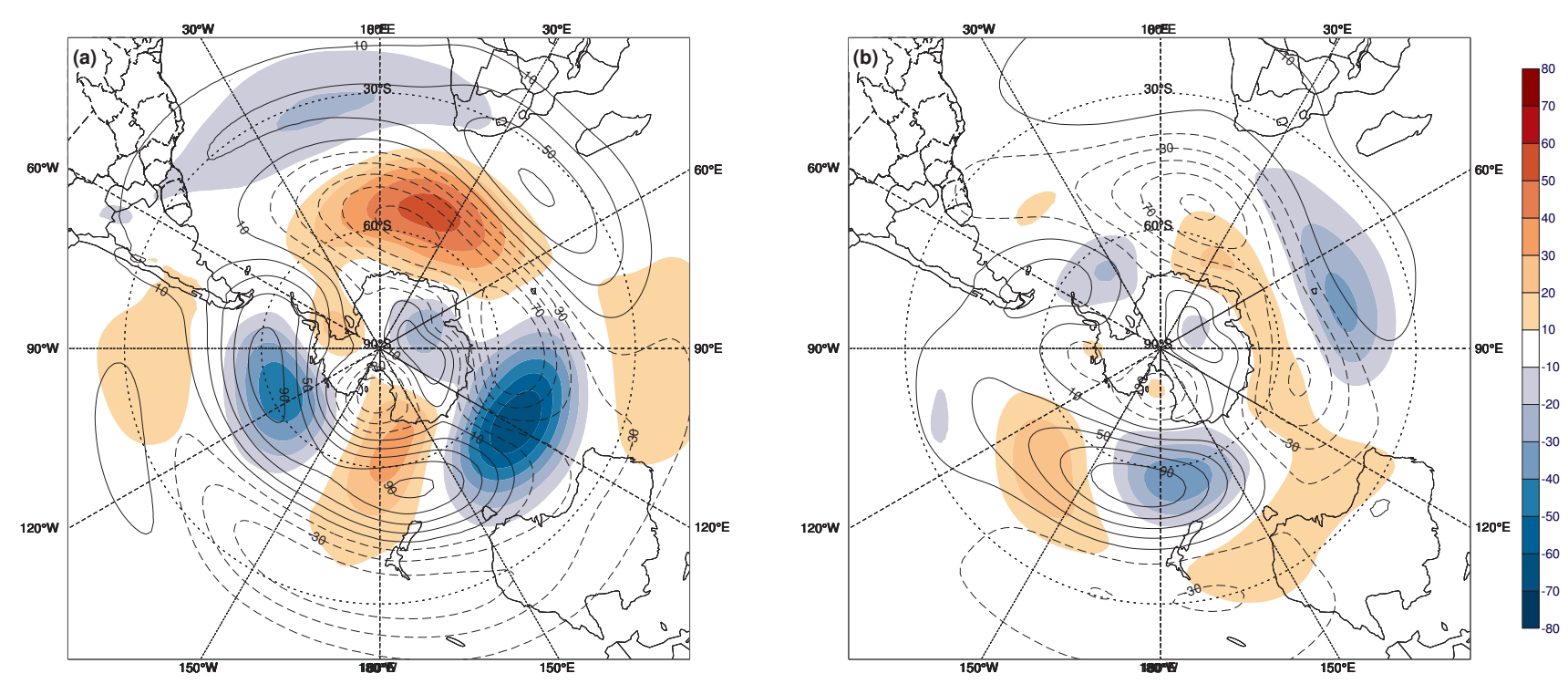

Fig. $6500 \mathrm{hPa}$ geopotential height anomaly (meters) biases (HadGEM2-ES minus ERA-Interim) from the zonal mean for (a) JJA and (b) DJF. Black line contours show ERA-Interim climatology for the period 1979-2005 and dashed contours indicate negative values.

\subsubsection{Summer}

During the austral summer the jets (Figs. 7b, d and f) ${ }^{32}$ tend to move poleward and as a result the two waveg- ${ }^{33}$ uides disappear, with this variability (one single jet ${ }_{34}$ stream) being reflected directly in the storm track pat- 35 tern (Fig. 2a and b) (Chang 1999; Rao et al 2002; 36 Hoskins and Hodges 2005; Inatsu and Hoskins 2006; 37 Rivière 2011). Although the main ST pattern is well 38 represented in HadGEM2-ES it tends to underestimate ${ }_{39}$ the baroclinicity in tropical and extratropical latitudes, 40 as shown in Figure 3c and d. In contrast with the win- 41 ter baroclinicity biases (Fig. 3a), where the maximum ${ }_{42}$ bias were found in the Indian Ocean, the largest biases 43 are found in the Pacific Ocean in summer (Fig. 3c) at ${ }_{44}$ $250 \mathrm{hPa}$. Positive biases can be seen on the equatorward 45 side of the climatological position of the ST which can ${ }_{46}$ be related to the narrowing of the storm tracks. Two 47 negative bias peaks are found to the south of South 48 Africa and Australia and adjacent oceans (Fig. 3c). In 49 the northeast of Argentina and Uruguay other minor 50 negative baroclinicity biases are observed and this area ${ }_{51}$ corresponds with the track (Fig. 2a), genesis (Fig. 2d) 52 and mean growth negative biases (Fig. 2l). The baroclinicity biases at $250 \mathrm{hPa}$ in the high latitudes, over $50^{\circ} \mathrm{S}$, are close to zero.

The summer temperature zonal mean (Fig. 7a, c and 56 e) indicates that the cold biases at upper levels (300-57 $100 \mathrm{hPa}$ ) are weaker and more poleward (around $\left.70^{\circ} \mathrm{S}\right)_{58}$ than in winter over the southern oceans. The temper- 59 ature positive bias pattern persists in the tropopause over tropical latitudes in the summer season and may indicate a systematic error because it can also be seen in the autumn and spring (figures not shown).

The zonal mean zonal wind (Figs. 7b,d and f) shows that the jet biases extend from upper levels toward lower levels. Simpson et al (2013a,b) found the same pattern which may indicate a link with the Southern Annular Mode (SAM) during the summer season because of a lack of negative feedbacks from planetary waves and a delay in the breakup of the polar vortex. In general, the summer zonal wind biases are smaller than other seasons related to the better representation of the single eddy-driven. Another possibility is suggested by Sun et al (2014), they found that ozone depletion can delay the polar vortex breakup, inducing a deep response in planetary wave drag and associated eddy-driven circulation. Therefore, the jet position biases seem associated with the upper tropospheric temperature negative biases and this is likely associated with the track density biases (Fig. 1c) in the Southern Hemisphere oceans (Orlanski 2013; Barnes and Polvani 2013; Barnes et al 2014).

The results during the summer also support the hypothesis that HadGEM2-ES does not simulate the Rossby waveguide correctly, as described above for winter. During the summer, the strongest SST positive biases are observed over the Atlantic and Indian oceans at a latitude of $70^{\circ} \mathrm{S}$ (Fig. 4b). Consequently, there is a strong zonal wind bias over the Indian Ocean that ex- 
tends from the surface to high levels, which is strong on 53 the equatorward side and weaker on the poleward side around $250 \mathrm{hPa}$ (Fig. $7 \mathrm{~d}$ ). This jet bias extends toward 54 the Pacific and enhances the baroclinicity at upper lev- 55 els, mainly over Australia and New Zealand, as shown 56 in Figure 3c. These differences occur over a well-known 57 region of the Rossby Wave source during DJF (Shimizu 58 and de Albuquerque Cavalcanti 2011) and it seems to 59 indicate a change of the waveguide and ST over the 60 southern oceans.

Similar to the other large-scale biases, the $500 \mathrm{hPa}_{63}$ geopotential biases (Fig. 6b) in the summer are also ${ }_{64}$ much weaker than in winter, however, only the $\mathrm{SST}_{65}$ biases (Fig. 4b) are stronger. The large geopotential ${ }_{66}$ negative bias peak near to New Zealand is related to 67 the positive temperature bias in the lower troposphere over high latitudes that result in a geopotential slightly ${ }^{68}$ higher relative to ERA-Interim. This result corresponds ${ }^{69}$ with previous studies, such as Hoskins and Hodges (2005 ${ }^{\circ}$ that found the same region near to New Zealand is also ${ }^{71}$ a region with a maximum of anticyclone genesis, which ${ }^{72}$ is more intense in the autumn and summer. In this way, ${ }^{73}$ the zonal wind anomalies around this low height bias ${ }^{74}$ can increase the flow equatorward of south Australia ${ }^{75}$ and poleward of $50^{\circ} \mathrm{S} / 60^{\circ} \mathrm{S}$, which are consistent with ${ }^{76}$ the track density bias dipole (Fig. 2c) close to New ${ }^{77}$ Zealand in a region where the storm track densities are ${ }^{78}$ most polewards (Fig. 2b). These results agree with the ${ }^{79}$ patterns at $500 \mathrm{hPa}$ found by Ummenhofer et al (2013) ${ }^{80}$ using a general atmospheric circulation model and it ${ }^{81}$ seems to be related to blocking systems displaced over ${ }^{82}$ this region (Fig. 6b). Besides, this pattern is also con- ${ }^{83}$ sistent with the negative lysis biases (Fig. 2i) on the ${ }^{84}$ Antarctic coast around $150^{\circ} \mathrm{W}$ and the positive gene- ${ }^{85}$ sis biases (Fig. 2f) over the east of New Zealand and ${ }^{86}$ the Tasman Sea. Also, HadGEM2-ES tends to repre- ${ }^{87}$ sent positive geopotential height anomalies in this re- ${ }^{88}$ gion (Fig. 6b) and this pattern can help to explain the ${ }^{89}$ fewer cyclones near to Antarctica and more cyclones ${ }^{90}$ over the equatorward side of the ST in the track den- ${ }^{91}$ sity biases (Fig. 2c).

During the austral summer the SST biases are stronger than winter as shown in Figure 4b. The positive bias 95 peaks over Atlantic and Indian oceans seem like the 96 winter season, however, those in the Pacific Ocean are 97 amplified toward the equator between longitudes of $90^{\circ} \mathrm{W}_{8}$ and $180^{\circ} \mathrm{W}$. Also, the positive biases at poleward lat-99 itudes and a small at equatorward latitudes (Fig. 4b) 100 result in a weaker temperature gradient that than seen 101 in the reanalysis. Therefore, the response is that the102 $\mathrm{ST}$ is more aligned with the location of the tempera-103 ture gradient changes, as shown in Figures 2c and 4b. 104

\section{Summary and conclusions}

The use of HadGEM2-ES, a modern earth system climate model and the ERA-Interim reanalysis together with objective cyclone tracking techniques has enabled a detailed view of the Southern Hemisphere storm tracks and an assessment of the performance of HadGEM2-ES with respect to cyclones and the STs. The comparison of the cyclone tracking statistics was performed for winter (JJA) and summer (DJF). The results show that in general the Southern Hemisphere storm tracks correspond well between the model and reanalysis, with some regions slightly displaced in the variables analyzed. However, zonal biases in the track density were found, mainly around Antarctica and in the Indian Ocean. A summary of the results are outlined below.

- The storm tracks in the Southern Hemisphere have larger width with more cyclones on the equatorward side and less over the poleward side. This equatorward bias pattern has high correspondence with the upper level jet differences. These results were also found by Lambert et al (2002); Bengtsson et al (2006) using the previous generations of climate models. Thus, the results show that there is a link between the equatorward bias and the low resolution in the historical experiments of HadGEM2-ES. This specific issue will be explored in a further study.

- The greatest differences in the track density was observed in the Indian Ocean, between Antarctica and Australia, during the winter season. These biases indicate a poor representation of the winter storm track spiral towards Antarctic in the HadGEM2-ES experiment. The results indicate that this problem is partially caused by two regional factors, the first is because of the negative genesis biases in the climatological cyclogenesis regions over South America, Antarctic Peninsula and the Antarctic coast approximately at longitude $150^{\circ} \mathrm{E}$, that is reflected in the number of cyclones in the ST. The second factor is due to model resolution and the representation of the Andes Mountains. The positive genesis biases over South Africa, Tasmania Sea and east of New Zealand are apparently associated with the problems related above in the winter season.

- In general, the HadGEM2-ES large-scale biases tend to have a similar pattern to the ST biases. In the upper levels, large cold biases were found over the extratropical and Polar Regions, which is a result of the equatorward jet position bias of the subtropical jet and a weaker polar jet (eddy-driven). The analysis shows that the split jet during the winter is a model problem linking these biases, including the geopotential anomaly and SST biases. 

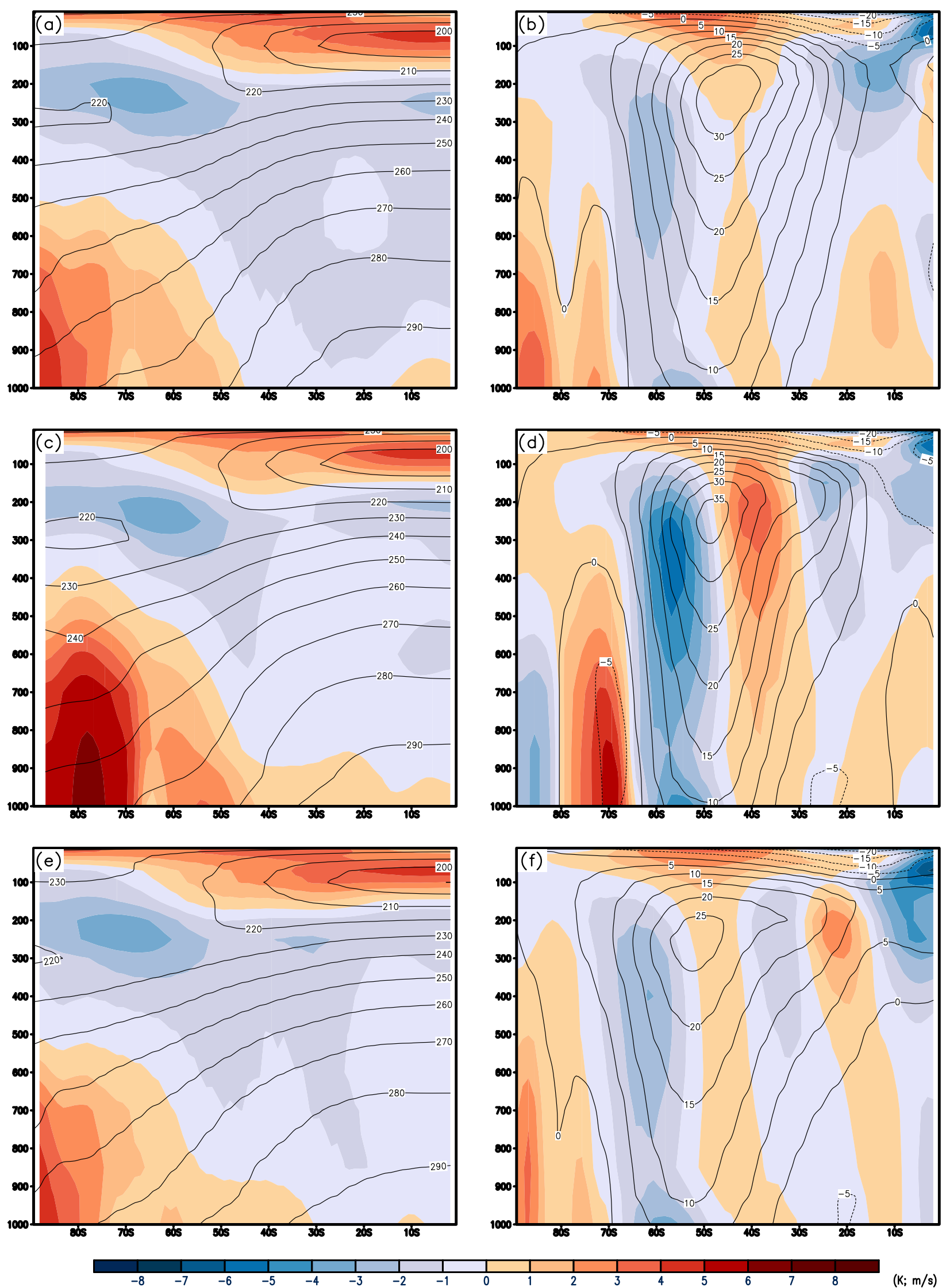

Fig. 7 As in Fig.5 but for the DJF. 
- Over the oceans, the track, genesis, mean growth/decay References rate densities biases are possibly associated with the poor representation of location and variability of ocean fronts.

These results have shown that there is agreement between the climate model and the reanalysis, however, there are differences and it is important to be aware of these when using the model to study the impact of perturbation experiments such as removing the Amazon Forest. An important feature that needs to be considered is, that although the representation of cyclones in modern reanalyses has seen considerable improvement in recent years in terms of their agreement, however, some aspects such as the cyclogenesis in the lee of Andes Mountains, continue to be not well represented (Hodges et al 2011). In addition, differences are still apparent in the storm track density during the winter season. These biases were already found in previous storm track studies using the previous generation of climate models (e.g. Bengtsson et al (2006); Ulbrich et al (2009); Chang et al (2013)), and also in the new generation of CMIP5 models for the North Atlantic (e.g. Zappa et al (2013a, 2014)), and in this study, using the HadGEM2-ES historical simulations for CMIP5, a similar pattern of zonal biases for Southern Hemisphere was found.

In summary, the ST comparison between the historical experiment of HadGEM2-ES and the ERA-Interim reanalysis showed that the HadGEM2-ES has a relatively good representation of extratropical cyclones in the Southern Hemisphere. The storm track features in HadGEM2-ES are consistent in many aspects with ERA-Interim. So although HadGEM2-ES has biases in the representation of cyclones in the SH, consistent with many other climate models, the results in this paper provide confidence in using HadGEM2-ES for future climate studies. Particularly, in a second paper, that reports the importance of the Amazon Forest to the SH STs.

Acknowledgements The authors would like to acknowledge the ECMWF for making the ERA-Interim data available and the Dr Fernando Ii for Metview support. They would also like to express their appreciation of comments made by reviewers. This work was conducted during a scholarship supported by the Sandwich Doctoral Program CAPES/INPE at the University of Reading - United Kingdom. Financed by CAPES - Brazilian Federal Agency for Support and Evaluation of Graduate Education within the Ministry of Education of Brazil.

Barnes EA, Polvani L (2013) Response of the midlatitude jets, and of their variability, to increased greenhouse gases in the CMIP5 models. Journal of Climate 26(18):7117-7135, DOI 10.1175/JCLI-D-12-00536.1

Barnes EA, Barnes NW, Polvani LM (2014) Delayed southern hemisphere climate change induced by stratospheric ozone recovery, as projected by the CMIP5 models. Journal of Climate 27(2):852-867, DOI 10.1175/JCLI-D-1300246.1

Bellouin N, Collins WJea (2011) The HadGEM2 family of Met Office Unified Model Climate configurations. Geoscientific Model Development Discussions 4(2):765-841, DOI 10.5194/gmdd-4-765-2011, URL http://www.geoscimodel-dev-discuss.net/4/765/2011/

Bengtsson L, Hodges KI, Roeckner E (2006) Storm tracks and climate change. Journal of Climate 19(15):3518-3543, DOI 10.1175/JCLI3815.1

Berbery EH, Vera CS (1996) Characteristics of the Southern Hemisphere Winter Storm Track with Filtered and Unfiltered Data. Journal of the Atmospheric Sciences 53(3):468-481, DOI 10.1175/15200469(1996)053;0468:COTSHW ¿2.0.CO;2

Bjerknes V, Solberg H (1922) Life cycle of ciclones and the polar front theory of atmospheric circulation. Geofysiske Publikasjoner 3(1):3-18

Catto JL, Shaffrey LC, Hodges KI (2010) Can Climate Models Capture the Structure of Extratropical Cyclones? Journal of Climate 23(7):1621-1635, DOI 10.1175/2009JCLI3318.1, URL http://journals.ametsoc.org/doi/abs/10.1175/ 2009JCLI3318.1

Catto JL, Shaffrey LC, Hodges KI (2011) Northern Hemisphere Extratropical Cyclones in a Warming Climate in the HiGEM HighResolution Climate Model. Journal of Climate 24(20):5336-5352, DOI 10.1175/2011JCLI4181.1, URL http://journals.ametsoc.org/doi/abs/10.1175/ 2011JCLI4181.1

Chang EK (2017) Projected Significant Increase in the Number of Extreme Extratropical Cyclones in the Southern Hemisphere. Journal of Climate 30(13):4915-4935, DOI 10.1175/JCLI-D-16-0553.1

Chang EKM (1993) Downstream Development of Baroclinic Waves As Inferred from Regression Analysis. DOI 10.1175/1520-0469(1993)050;2038:DDOBWA ¿2.0.CO;2

Chang EKM (1999) Characteristics of Wave Packets in the Upper Troposphere. Part II: Seasonal and Hemispheric Variations. DOI 10.1175/15200469(1999)056;1729:COWPIT¿2.0.CO;2

Chang EKM, Guo Y, Xia X (2012) CMIP5 multimodel ensemble projection of storm track change under global warming. Journal of Geophysical Research Atmospheres 117(23):1-19, DOI 10.1029/2012JD018578

Chang EKM, Guo Y, Xia X, Zheng M (2013) Storm-Track Activity in IPCC AR4/CMIP3 Model Simulations. Journal of Climate 26(1):246260, DOI 10.1175/JCLI-D-11-00707.1, URL http://journals.ametsoc.org/doi/abs/10.1175/JCLID-11-00707.1

Collins WJ, Bellouin N, Doutriaux-Boucher M, Gedney $\mathrm{N}$, Halloran P, Hinton T, Hughes J, Jones CD, Joshi M, Liddicoat S, Martin G, O'Connor F, Rae J, Senior C, Sitch S, Totterdell I, Wiltshire A, Woodward S (2011) Development and evaluation of an Earth- 
System model - HadGEM2. Geoscientific Model Development 4(4):1051-1075, DOI 10.5194/gmd-4-1051-2011, URL http://www.geosci-model-dev.net/4/1051/2011/

Dee DP, Uppala SM, Simmons AJ, Berrisford P, Poli P, Kobayashi S, Andrae U, Balmaseda MA, Balsamo G, Bauer P, Bechtold P, Beljaars ACM, van de Berg L, Bidlot J, Bormann N, Delsol C, Dragani R, Fuentes M, Geer AJ, Haimberger L, Healy SB, Hersbach H, Hólm EV, Isaksen L, Kållberg P, Köhler M, Matricardi M, McNally AP, Monge-Sanz BM, Morcrette JJ, Park BK, Peubey C, de Rosnay P, Tavolato C, Thépaut JN, Vitart F (2011) The ERA-Interim reanalysis: configuration and performance of the data assimilation system. Quarterly Journal of the Royal Meteorological Society 137(656):553-597, DOI 10.1002/qj.828, URL http://doi.wiley.com/10.1002/qj.828

Eady ET (1949) Long Waves and Cyclone Waves. Tellus 1(3):33-52, DOI
$10.1111 / \mathrm{j} .2153-3490.1949 . t b 01265 . x$, http://tellusa.net/index.php/tellusa/article/view/8507

Evans JL, Braun A (2012) A climatology of subtropical cyclones in the South Atlantic. Journal of Climate 25(21):7328-7340, DOI 10.1175/JCLI-D-11-00212.1

Fyfe JC (2003) Extratropical Southern Hemisphere Cyclones: Harbingers of Climate Change? Journal of Climate 16(17):2802-2805, DOI 10.1175/15200442(2003)016;2802:ESHCHO ¿2.0.CO;2

Gan MA, Rao VB (1991) Surface Cyclogenesis over South America. Monthly Weather Review 119(5):1293-1302, DOI 10.1175/1520-0493(1991)119;1293:SCOSA ¿2.0.CO;2

Gan MA, Rao VB (1994) The Influence of the Andes Cordillera on Transient Disturbances. DOI 10.1175/15200493(1994)122ز1141:TIOTAC ¿2.0.CO;2

Gan MA, Rao VB (1996) Case studies of cyclogenesis over South America. Meteorological Applications 3(4):359-367, DOI 10.1002/met.5060030410, URL http://doi.wiley.com/10.1002/met.5060030410

Gomes HB, Ambrizzi T, Herdies DL, Hodges K, Pontes da Silva BF (2015) Easterly Wave Disturbances over Northeast Brazil: An Observational Analysis. Advances in Meteorology 2015:1-20, DOI 10.1155/2015/176238, URL http://www.hindawi.com/journals/amete/2015/176238/

Hodges KI (1994) A General Method for Tracking Analysis and Its Application to Meteorological Data. Monthly Weather Review 122(11):2573-2586, DOI 10.1175/15200493(1994)122;2573:AGMFTA ¿2.0.CO;2

Hodges KI (1995) Feature Tracking on the Unit Sphere. DOI 10.1175/1520-0493(1995)123;3458:FTOTUS ¿2.0.CO;2

Hodges KI (1996) Spherical Nonparametric Estimators Applied to the UGAMP Model Integration for AMIP. Monthly Weather Review 124(12):2914-2932, DOI 10.1175/1520-0493(1996)124;2914:SNEATT ¿2.0.CO;2

Hodges KI (1999) Adaptive Constraints for Feature Tracking. Monthly Weather Review 127(6):1362-1373, DOI 10.1175/1520-0493(1999)127¡1362:ACFFT ¿2.0.CO;2

Hodges KI, Hoskins BJ, Boyle J, Thorncroft C (2003) A Comparison of Recent Reanalysis Datasets Using Objective Feature Tracking: Storm Tracks and Tropical Easterly Waves. Monthly Weather Review 131(9):2012-2037, DOI 10.1175/1520-0493(2003)131¡2012:ACORRD ¿2.0.CO;2

Hodges KI, Lee RW, Bengtsson L (2011) A Comparison of Extratropical Cyclones in Recent Reanalyses ERA-Interim, NASA MERRA, NCEP CFSR, and JRA-25. Journal of Climate 24(18):4888-4906, DOI 10.1175/2011JCLI4097.1, URL http://journals.ametsoc.org/doi/abs/10.1175/

\section{JCLI4097.1}

Hoskins BJ, Ambrizzi T (1993) Rossby Wave Propagation on a Realistic Longitudinally Varying Flow. Journal of the Atmospheric Sciences 50(12):1661-1671, DOI 10.1175/1520-0469(1993)050;1661:RWPOAR ¿2.0.CO;2

Hoskins BJ, Hodges KI (2002) New Perspectives on the Northern Hemisphere Winter Storm Tracks. Journal of the Atmospheric Sciences 59(6):1041-1061, DOI 10.1175/1520-0469(2002)059;1041:NPOTNH ¿2.0.CO;2

Hoskins BJ, Hodges KI (2005) A New Perspective on Southern Hemisphere Storm Tracks. Journal of Climate 18(20):4108-4129, DOI 10.1175/JCLI3570.1, URL http://journals.ametsoc.org/doi/abs/10.1175/JCLI3570.1

Inatsu M, Hoskins BJ (2004) The zonal asymmetry of the Southern Hemisphere winter storm track. Journal of Climate 17(24):4882-4892, DOI 10.1175/JCLI-3232.1

Inatsu M, Hoskins BJ (2006) The Seasonal and Wintertime Interannual Variability of the Split Jet and the StormTrack Activity Minimum near New Zealand. Journal of the Meteorological Society of Japan 84(3):433-445, DOI $10.2151 /$ jmsj.84.433

Inatsu M, Mukougawa H, Xie SP (2002) Tropical and Extratropical SST Effects on the Midlatitude Storm Track. Journal of the Meteorological Society of Japan 80(4B):10691076, DOI 10.2151/jmsj.80.1069

IPCC (2013) Working Group I Contribution to the IPCC Fifth Assessment Report - Summary for Policymakers. In: Climate Change 2013: The Physical Science Basis, pp 1-36, URL http://eprints.utas.edu.au/4774/

Jones CD, Hughes JK, Bellouin Nea (2011) The HadGEM2ES implementation of CMIP5 centennial simulations. DOI 10.5194/gmdd-4-689-2011

Jones DA, Simmonds I (1993) A climatology of Southern Hemisphere extratropical cyclones. Climate Dynamics 9(3):131-145, DOI 10.1007/BF00209750

Jones PD, Harpham C (2013) Estimation of the absolute surface air temperature of the Earth. Journal of Geophysical Research: Atmospheres 118(8):3213-3217, DOI 10.1002/jgrd.50359, URL http://doi.wiley.com/10.1002/jgrd.50359

Kidston J, Vallis GK (2012) The Relationship between the Speed and the Latitude of an Eddy-Driven Jet in a Stirred Barotropic Model. Journal of the Atmospheric Sciences 69(11):3251-3263, DOI 10.1175/JAS-D-11-0300.1, URL http://journals.ametsoc.org/doi/abs/10.1175/JASD-11-0300.1

Lambert S, Sheng J, Boyle J (2002) Winter cyclone frequencies in thirteen models participating in the Atmospheric Model Intercomparison Project (AMIP1). Climate Dynamics 19(1):1-16, DOI 10.1007/s00382-001-0206-8, URL http://link.springer.com/10.1007/s00382-001-0206-8

Lin JL, Qian T, Shinoda T (2014) Stratocumulus clouds in Southeastern pacific simulated by eight CMIP5-CFMIP global climate models. Journal of Climate 27(8):30003022, DOI 10.1175/JCLI-D-13-00376.1

Marengo JA, Soares WR, Saulo C, Nicolini M (2004) Climatology of the low-level jet east of the Andes as derived from the NCEP-NCAR reanalyses: Characteristics and temporal variability. Journal of Climate 17(12):2261-2280, DOI 10.1175/15200442(2004)017¡2261:COTLJE 22.0. CO;2

Martin GM, Bellouin N, Collins WJ, Al E (2011) The HadGEM2 family of Met Office Unified Model climate configurations. Geoscientific Model Development 4(3):723-757, DOI 10.5194/gmd-4-723-2011 
Nakamura H, Shimpo A (2004) Seasonal variations in the Southern Hemisphere storm tracks and jet streams as revealed in a reanalysis dataset. Journal of Climate 17(9):1828-1844, DOI 10.1175/15200442(2004)017;1828:SVITSH ¿2.0.CO;2

Nakamura M (2012) Impacts of SST Anomalies in the Agulhas Current System on the Regional Climate Variability. Journal of Climate 25(4):12131229, DOI 10.1175/JCLI-D-11-00088.1, URL http://journals.ametsoc.org/doi/abs/10.1175/JCLID-11-00088.1

O'Reilly CH, Czaja A (2015) The response of the Pacific storm track and atmospheric circulation to Kuroshio Extension variability. Quarterly Journal of the Royal Meteorological Society 141(686):52-66, DOI 10.1002/qj.2334, URL http://doi.wiley.com/10.1002/qj.2334

Orlanski I (2013) What Controls Recent Changes in the Circulation of the Southern Hemisphere: Polar Stratospheric or Equatorial Surface Temperatures? Atmospheric and Climate Sciences 03(04):497-509, DOI 10.4236/acs.2013.34052

Parise CK, Calliari LJ, Krusche N (2009) Extreme storm surges in the south of Brazil: Atmospheric conditions and shore erosion. Brazilian Journal of Oceanography 57(3):175-188, DOI 10.1590/S1679-87592009000300002

Rao VB, do Carmo AMC, Franchito SH (2002) Seasonal Variations in the Southern Hemisphere Storm Tracks and Associated Wave Propagation. Journal of the Atmospheric Sciences 59(6):1029-1040, DOI 10.1175/15200469(2002)059;1029:SVITSH $i 2.0 . C O ; 2$

Reboita MS, da Rocha RP, Ambrizzi T, Sugahara S (2010) South Atlantic Ocean cyclogenesis climatology simulated by regional climate model (RegCM3). Climate Dynamics 35(7):1331-1347, DOI 10.1007/s00382-009-0668-7, URL http://dx.doi.org/10.1007/s00382-009-0668-7 http://link.springer.com/10.1007/s00382-009-0668-7

Rivière G (2011) A Dynamical Interpretation of the Poleward Shift of the Jet Streams in Global Warming Scenarios. Journal of the Atmospheric Sciences 68(6):1253-1272, DOI 10.1175/2011JAS3641.1

Shimizu MH, de Albuquerque Cavalcanti IF (2011) Variability patterns of Rossby wave source. Climate Dynamics 37(3-4):441-454, DOI 10.1007/s00382-010-0841-z, URL http://link.springer.com/10.1007/s00382-010-0841-z

Silva Dias MAF, Dias J, Carvalho LMV, Freitas ED, Silva Dias PL (2013) Changes in extreme daily rainfall for São Paulo, Brazil. Climatic Change 116(3-4):705-722, DOI 10.1007/s10584-012-0504-7

Simmonds I, Keay K (2000) Mean southern hemisphere extratropical cyclone behavior in the 40-year NCEP-NCAR reanalysis. Journal of Climate 13(5):873-885, DOI 10.1175/1520-0442(2000)013;0873:MSHECB ¿2.0.CO;2

Simpson IR, Hitchcock P, Shepherd TG, Scinocca JF (2013a) Southern Annular Mode Dynamics in Observations and Models. Part I: The Influence of Climatological Zonal Wind Biases in a Comprehensive GCM. Journal of Climate 26(11):39533967, DOI 10.1175/JCLI-D-12-00348.1, URL http://journals.ametsoc.org/doi/abs/10.1175/JCLID-12-00348.1

Simpson IR, Shepherd TG, Hitchcock P, Scinocca JF (2013b) Southern Annular Mode Dynamics in Observations and Models. Part II: Eddy Feedbacks. Journal of Climate 26(14):52205241, DOI 10.1175/JCLI-D-12-00495.1, URL http://journals.ametsoc.org/doi/abs/10.1175/JCLI-
D-12-00495.1

Sinclair MR (1994) An Objective Cyclone Climatology for the Southern Hemisphere. Monthly Weather Review 122(10):2239-2256, DOI 10.1175/15200493(1994)122;2239:AOCCFT¿2.0.CO;2

Sinclair MR (1995) A Climatology of Cyclogenesis for the Southern Hemisphere. Monthly Weather Review 123(6):1601-1619, DOI 10.1175/1520 0493(1995)123;1601:ACOCFT¿2.0.CO;2

Sinclair MR (1997) Objective Identification of Cyclones and Their Circulation Intensity, and Climatology. Weather and Forecasting 12(3):595-612, DOI 10.1175/15200434(1997)012;0595:OIOCAT ¿2.0.CO;2

Sprenger M, Martius O, Arnold J (2013) Cold surge episodes over southeastern Brazil - A potential vorticity perspective. International Journal of Climatology 33(12):27582767, DOI 10.1002/joc.3618

Sun L, Chen G, Robinson WA (2014) The Role of Stratospheric Polar Vortex Breakdown in Southern Hemisphere Climate Trends. Journal of the Atmospheric Sciences 71(7):2335-2353, DOI 10.1175/JAS-D-13-0290.1, URL http://journals.ametsoc.org/doi/abs/10.1175/JASD-13-0290.1

Taljaard JJ (1972) Synoptic Meteorology of the southern hemisphere. In: Newton CW (ed) Meteorology of the Southern Hemisphere, American Meteorological Society, Boston, chap 35, p 263

Tamarin T, Kaspi Y (2017) Mechanisms Controlling the Downstream Poleward Deflection of Midlatitude Storm Tracks. Journal of the Atmospheric Sciences 74(2):553-572, DOI 10.1175/JAS-D-16-0122.1, URL http://journals.ametsoc.org/doi/10.1175/JAS-D-160122.1

Taylor KE, Stouffer RJ, Meehl GA (2012) An overview of CMIP5 and the experiment design. DOI 10.1175/BAMSD-11-00094.1

Ulbrich U, Leckebusch GC, Pinto JG (2009) Extratropical cyclones in the present and future climate: a review. Theoretical and Applied Climatology 96(1-2):117-131, DOI 10.1007/s00704-008-0083-8, URL http://link.springer.com/10.1007/s00704-008-0083-8

Ummenhofer CC, Mcintosh PC, Pook MJ, Risbey JS (2013) Impact of surface forcing on southern hemisphere atmospheric blocking in the Australia-New Zealand sector. Journal of Climate 26(21):8476-8494, DOI 10.1175/JCLID-12-00860.1

Woollings T (2010) Dynamical influences on European climate: an uncertain future. Philosophical Transactions of the Royal Society A: Mathematical, Physical and Engineering Sciences 368(1924):3733-3756, DOI 10.1098/rsta.2010.0040

Woollings T, Hoskins B, Blackburn M, Hassell D, Hodges K (2010) Storm track sensitivity to sea surface temperature resolution in a regional atmosphere model. Climate Dynamics 35(2-3):341-353, DOI 10.1007/s00382-009-0554-3, URL http://link.springer.com/10.1007/s00382-009-05543

Zappa G, Shaffrey LC, Hodges KI (2013a) The Ability of CMIP5 Models to Simulate North Atlantic Extratropical Cyclones*. Journal of Climate 26(15):5379-5396, DOI 10.1175/JCLI-D-12-00501.1

Zappa G, Shaffrey LC, Hodges KI, Sansom PG, Stephenson DB (2013b) A Multimodel Assessment of Future Projections of North Atlantic and European Extratropical Cyclones in the CMIP5 Climate Models. Journal of Climate 26(16):5846-5862, DOI 10.1175/JCLI-D-12-00573.1, 
URL http://journals.ametsoc.org/doi/10.1175/JCLI-D12-00573.1

Zappa G, Masato G, Shaffrey L, Woollings T, Hodges K (2014) Linking Northern Hemisphere blocking and storm track biases in the CMIP5 climate models. Geophysical Research Letters 41(1):135-139, DOI 10.1002/2013GL058480, URL http://doi.wiley.com/10.1002/2013GL058480 